\title{
Bone biomarkers of ovariectomised rats after leptin therapy
}

\author{
Khaled A. Abdel-Sater ${ }^{1}$, Hamdy Mansour ${ }^{2}$ \\ Department of Physiology, Al-Azhar Faculty of Medicine, Assiut, Egypt. Khaled_71111@yahoo.com
}

\begin{abstract}
Background and aim: Under physiological conditions, maintenance of skeletal mass is the result of a tightly coupled process of bone formation and bone resorption. Disease states, osteoporosis included, arise when this delicate balance is disrupted, such as in menopause. The aim of the present work was to study the effect of leptin supplementation on bone metabolism in ovariectomized adult female rats by measuring indices of bone biomarkers.

Methods: Forty adult female albino rats were chosen as an animal model for this study and divided into the four equal groups ( $n=10 /$ group): Group I (control SHAM-operated group) received a single dose of buffer solution i.p. daily for eight weeks. Group II (ovariectomy group) received a single dose of buffer solution i.p. daily for eight weeks. Group III (alendronate group): Ovariectomized rats that received alendronate $0.1 \mathrm{mg} / \mathrm{kg}$ body weight i.p. daily for eight weeks. Group IV (leptin group): Ovariectomized rats that received leptin $(10 \mu \mathrm{gg} / \mathrm{kg}$ body weight) i.p. daily for eight weeks. The obtained serum is required for determination of: Serum osteocalcin, alkaline phosphatase, calcium and phosphorous levels.

Results: The obtained data revealed that treatment with alendronate or leptin caused a significant decrease of serum osteocalcin, specific bone alkaline phosphatase and urinary deoxypyridinoline levels compared to ovariectomy group, and there was no significant difference between both drugs.

Conclusion: Leptin prevents ovariectomy induced increases in bone turnover in rats. Leptin therapy has a significant effect in treatment of ovariectomy induced osteoporosis in rats (Tab. 1, Ref. 32). Full Text in PDF www.elis.sk. Key words: leptin, bone metabolism, ovariectomy, osteoporosis, bone biomarkers.
\end{abstract}

Bone structure is preserved via a dynamic procedure of bone turnover, a coupled balance between bone resorption and bone formation. Osteoporosis is a metabolic bone disease associated with an unequilibrated bone remodeling due to decreased bone formation or accelerated bone resorption (Saleh and Saleh, 2011). This increases bone fragility, which means that fractures can occur after low-energy traumas (Byun and Lee, 2010). Osteoporosis is three times more common in women than in men, partly because women have a lower peak bone mass and partly because of the estrogen hormonal changes that occur in the menopause (Canalis, 2010).

Remodeling maintains the mechanical integrity of the skeleton by replacing old bone with new (Jackson et al, 2011). It is controlled by several circulating hormones, including parathyroid hormone, 1 $\alpha, 25$-dihydroxycholecalciferol (calcitriol), gonadal sex hormones and adrenal androgens (dehydroepiandrosterone and androstenedione) (Robling et al, 2006). Several cytokines released in the bone marrow increase the rate of bone turnover. TNF- $\alpha$, interleukin- 1 and interleukin- 6 , all stimulate bone resorption in vitro and in vivo, and may initiate the bone loss-induced by estrogen deficiency (Weitzmann and Pacific, 2006). Interactions between environmental factors such as dietary intake and physical exercise, as well as between genetic and environmental

${ }^{1}$ Department of Physiology, Al-Azhar Faculty of Medicine, Assiut, Egypt, and ${ }^{2}$ Department of Pharmacology, Al-Azhar Faculty of Medicine, Cairo, Egypt

Address for correspondence: Khaled A. Eliwa, Department of Physiology, Faculty of Medicine, Al-Azhar University, Egypt. factors, might play an important role in the acquisition of bone mineral mass (Deal, 2009).

Leptin, a cytokine-like hormone secreted by adipocytes, is known to regulate food intake but has also emerged as a significant factor in the regulation of bone mass (Cirmanová et al, 2008). Ducy et al (2000) have shown that in leptin-deficient and leptinreceptor-deficient mice there is abnormally high bone mass due to increased bone formation. In this study, it was also shown that an intracerebroventricular infusion of leptin in leptin-deficient mice resulted in bone loss with the bone of the treated animals regaining normal appearance. So, the aim of this study was to assess the possible effect of leptin supplementation compared to alendronate, as the standard treatment of osteoporosis on bone metabolism in ovariectomized adult female rats, by measuring indices of bone resorption and bone formation (bone biomarkers).

\section{Materials and methods}

\section{Materials}

Rat leptin was purchased from Calbiochem, La Jolla, CA, USA. Alendronate tablets (Fosamax, $10 \mathrm{mg}$ ) were brought from Fosamax-Merck Sharp \& Dome, Rome, Italy. Osteocalcin ELISA kit was obtained from Biomedical Technologies Inc., Stoughton, Mass., USA. Rat deoxypyridinoline ELISA kit was obtained from My Bio-Source California, USA. Alkaline phosphatase and calcium kits were purchased from Sigma Chemical Co.; St. Louis, MO. Phosphorous kit was obtained from Bio Merieux France. Thiopental sodium was brought from Sandoz GmbH, Kundl-Austria. 


\section{Animals model}

Forty Sprague-Dawley adult female rats (from Assiut university animal house) weighing 150-200 grams (4-6 months) (at the beginning of the experiment) were used. Rats were housed in boxes, 10 animals each, under standard conditions of temperature and humidity and a 12-hour light/dark cycle. The rats were fed with the standard diet of commercial chow and tap water and left to acclimatize to environment for two weeks prior to inclusion in the experiment. All experiments were performed during the same time of day, between 8 a.m and 2 p.m to avoid variations due to diurnal rhythms. Manipulations during the test were carried out by the same person (Noriyoshi et al, 2000). All of the procedures regarding the care and use of animals and animal experimentation in this study were complied with the Guide for the Care and Use of Laboratory Animals published by the US National Institutes of Health.

\section{Procedures}

Induction of osteoporosis by ovariectomy

A menopausal state in animals can be induced surgically by ovariectomy (OVX). Bilateral OVX was performed using a dorsal approach under i.p. sodium pentobarbital ( $40 \mathrm{mg} / \mathrm{kg}$ body weight) anesthesia (Turkozan et al, 2009). A skin incision (about 0.5-1.0 $\mathrm{cm}$ long) was made midway between the last rib and the cervix and about $1 \mathrm{~cm}$ lateral to the spinal muscles. A second parallel but shorter incision was made through the muscles under the incised skin area. A high degree of aseptic procedure was maintained throughout the operation. The ovary embedded in fat was withdrawn out and tied with a silk ligature to enclose the whole ovary and to avoid the inclusion of the adjacent fat as much as possible (Tarek and Hala, 2006). The ovary, tied up by the ligature, was cut away and the end of the uterus returned back to the peritoneal cavity. The cut edges of the muscles were sewn with catgut and those of the skin with silk. The ovary of the other side was then similarly removed through a separate incision. The SHAM-operated control rats had their dermal integuments, muscles and peritoneum sectioned, but underwent no excision of the ovaries. All the animals were cared with analgesia and antibiotics for equally after surgery. The success of ovariectomy was confirmed at necropsy by failure to detect ovarian tissue and by observation of marked atrophy of the uterine horns ( $\mathrm{Li}$ et al, 2002, Turkozan et al, 2009).

\section{Animal groupings/treatment}

At the 4th day post-surgery, rats were randomized to four groups, each of ten rats. Treatment was not started until the 7 th day post-OVX to allow the estrogen levels to become completely depleted (Burguera et al, 2001).

Group I (control group): SHAM-operated rats that received a single dose of phosphate buffer solution (PBS) given intraperitoneally (i.p.) daily for eight weeks.

Group II (OVX group): Rats in which osteoporosis was induced by bilateral OVX and received a single dose of PBS given i.p. daily for eight weeks (Alam et al, 2006).

Group III (alendronate group): Ovariectomized rats that received alendronate tablets $(10 \mathrm{mg})$ suspended in PBS $0.1 \mathrm{mg} / \mathrm{kg}$ body weight i.p. daily for eight weeks (Xiong et al, 2010). The alendronate tablets were used $10 \mathrm{mg}$ once daily - not $70 \mathrm{mg}$ once weekly - to become uniformed with leptin therapy.

Group IV (leptin group): Ovariectomized rats that received exogenous recombinant rat leptin $(10 \mu \mathrm{g} / \mathrm{kg}$ body weight $)$ dissolved in PBS (i.p.) daily for eight weeks (Konturek et al, 2001). The rats of all groups were weighed every week during the experiments.

\section{Collection of samples}

At the end of the experimental period, all animals were fasted overnight and separated and the urine of each animal was collected for measurement of deoxypyridinoline (DPD) during the 24-hour period before slaughtering. Animal was anaesthetized with thiopental sodium $40 \mathrm{mg} / \mathrm{kg}$ intraperitoneally. Blood was collected from carotid artery after sacrificing the animal. Serum supernatant was separated by centrifugation at 3000 cycles / min. and kept in deep freeze at $-70{ }^{\circ} \mathrm{C}$ for future use.

Determination of serum calcium and phosphorous levels

Serum calcium and phosphorous levels were measured by colorimetric method (Brown, 2010).

\section{Determination of bone turnover biomarkers}

Due to their high specification and sensitivity in clinical tests, biochemical markers are considered to be useful tools for estimating the rate of osteoporosis related to bone loss, as well as for monitoring the effectiveness of anti-resorptive therapies in osteoporosis (Stavropoulou et al, 2005). Bone formation was assessed by measuring serum osteocalcin and bone-specific alkaline phosphatase (BSALP), whereas bone resorption was assessed by measuring the DPD. DPD is a cross linked collagen in the bone that is excreted in the urine with collagen by osteoclastic activity (Byun and Lee, 2010).

\section{Bone formation biomarkers}

Determination of serum osteocalcin levels

This assay is based on the competitive binding of soluble osteocalcin in serum to a monoclonal antibody raised against human osteocalcin. Biotinylated osteocalcin $(100 \mu \mathrm{L})$ was added to a sterile 96-well streptavidin-coated microtiter plate and incubated for $30 \mathrm{~min}$ at room temperature. After three washes with washing solution, duplicate $20 \mu \mathrm{L}$ serum samples were pipetted into the wells, followed by $150 \mu \mathrm{L}$ of osteocalcin primary monoclonal antibody (diluted with primary incubation buffer at a volumetric ratio of 1:100). The mixtures were incubated for $60 \mathrm{~min}$ at room temperature on a microtiter mixing apparatus (300 rpm). The secondary antibody was added (100 $\mu \mathrm{L}$ per well) after washing the wells three times with washing solution. The incubation time was $60 \mathrm{~min}$, followed by washing and the addition of chromogenic substrate solution (tetramethylbenzidine in an acidic solution) for $15 \mathrm{~min}$ in the dark. The reaction was stopped by the addition of $100 \mu \mathrm{L}$ of stopping solution $\left(0.18 \mathrm{M} \mathrm{H}_{2} \mathrm{SO}_{4}\right)$ and the absorbance was measured at $450 \mathrm{~nm}$ with a $650 \mathrm{~nm}$ filter as reference (Stavropoulou et al, 2005, Byun and Lee, 2010). 
Tab. 1. Effects of leptin administration on serum osteocalcin, alkaline phosphatase, calcium and phosphorous levels in normal and ovariectomized rats.

\begin{tabular}{|c|c|c|c|c|}
\hline Parameters & Control group & OVX group & Alendronate group & Leptin group \\
\hline Final body weight (g) & $270.2 \pm 4.54 * * *$ & $320.3 \pm 5.247$ & $300.2 \pm 5.2$ & $275.3 \pm 9.5 * * *$ \\
\hline Final uterine weight $(\mathrm{g})$ & $2.32 \pm 0.11 * * *$ & $0.51 \pm 0.044$ & $1.33 \pm 0.16^{* * *}$ & $1.23 \pm 0.16^{* *}$ \\
\hline Osteocalcin (ng/ml) & $8.060 \pm 0.6709^{* * *}$ & $12.56 \pm 0.4587$ & $8.203 \pm 0.6379^{* * *}$ & $9.986 \pm 0.6678^{* * *}$ \\
\hline BSALP (IU\%) & $2.56 \pm 0.3 * * *$ & $6.08 \pm 0.26$ & $3.81 \pm 0.4 * *$ & $3.9 \pm 0.4 * *$ \\
\hline DPD (nmol/mmol creatinin) & $151.3 \pm 11.49 * * *$ & $219.6 \pm 9.36$ & $157.5 \pm 10.9^{* *}$ & $168 \pm 9.45^{* *}$ \\
\hline Calcium $(\mathrm{mg} \%)$ & $10.05 \pm 0.360^{* * *}$ & $5.618 \pm 0.517$ & $9.76 \pm 0.189 * * *$ & $5.13 \pm 0.32$ \\
\hline Phosphorous (mg\%) & $4.357 \pm 0.236$ & $5.271 \pm 0.291$ & $4.314 \pm 0.256$ & $5.7 \pm 0.33$ \\
\hline
\end{tabular}

Determination of serum bone specific alkaline phosphatase

Serum BSALP was measured by colorimetric method. The samples were pretreated by incubating $300 \mu$ of serum with 30 $\mu \mathrm{l}$ Triton $\mathrm{X}(20 \mathrm{~g} / \mathrm{l})$ for $30 \mathrm{~min}$ at $37^{\circ} \mathrm{C}$. An aqueous solution of wheat germ lectin (300 $\mu$ l Sigma-9640, $5 \mathrm{~g} / \mathrm{l}$ in distilled water) was then added, and the samples were mixed and incubated for $30 \mathrm{~min}$ at $37^{\circ} \mathrm{C}$. After centrifugation at $2000 \mathrm{~g}$ for $10 \mathrm{~min}$. BSALP was measured in the supernatant after precipitation with wheat germ lectin. The intra-assay CV was $5.1 \%$ and the inter-assay CV $6.8 \%$ at a mean value of $244 \mu / 1$ (Alam et al, 2006).

\section{Bone resorption biomarker}

Determination of Urinary Deoxypyridinoline Levels

DPD was measured by a competitive immunoassay using a rat monoclonal anti-DPD antibody. The urinary creatinine level was used to adjust DPD values for variations in urine volume. The results were expressed as nanomoles of DPD per millimole of creatinine to avoid the possible influence of the glomerular filtration rate (Byun and Lee, 2010).

\section{Statistical analysis}

Statistical analysis was done using the computer software program prism (Comshare's version of a decision support system $=\mathrm{DSS}$ ) version 3.3. Data were expressed as the means \pm SEM. Statistical significance for data was determined using the oneway analysis of variance (ANOVA) with Bonferroni's Multiple Comparison Test to find the inter-group significance. $\mathrm{p}<0.05$ was considered statistically significant.

\section{Results}

The mean values for body weight, uterine weight, osteocalcin, BSALP, DPD, calcium and phosphorous measurements in the control and the OVX groups and 60 days after the treatment with either alendronate or leptin were shown in the Table 1.

\section{Body and uterine weights}

The final body weight of the OVX group was significantly higher than that of the sham group $(\mathrm{p}<0.001)$. The OVX-induced body weight gain was significantly inhibited by leptin $(p<0.001)$. As expected, the final uterus weight was significantly $(p<0.001)$ reduced in the OVX group as compared to the sham group, indicating that estrogen deficiency resulted in the atrophy of the uterus of OVX rats. Leptin administration prevented the loss of uterine weight compared to the OVX group $(\mathrm{p}<0.01)$, but still resulted in a lower uterine weight than the sham group (Tab. 1).

\section{Serum Calcium and Phosphorous Levels}

The present data showed a significant decrease in serum calcium levels $(\mathrm{p}<0.001)$ in the OVX rats when compared to the control rats. The results in the Table 1 revealed that ovariectomized rats treated with alendronate demonstrated a significant increase $(p<0.001)$ of serum Ca levels accompanied with a non-significant decrease $(p>0.05)$ in serum $p$ level when compared to the ovariectomized rats. Ovariectomized rats treated with leptin showed a non- significant decrease $(\mathrm{p}>0.05)$ in serum Ca level accompanied with a non-significant increase $(p>0.05)$ in serum $p$ level when compared to the ovariectomized rats.

\section{Bone turnover biomarkers}

After 60 days, the levels of serum osteocalcin, serum BSALP and urinary DPD had significantly increased in the OVX group as compared to the groups I $(p<0.001)$, III and IV $(p<0.01)$. However, no significant differences in the serum levels BSALP were observed in the groups I, III and IV ( $p>0.05)$.

\section{Discussion}

\section{Body and Uterine Weights}

As seen in many studies, ovariectomized rats have significantly higher body weights compared to sham-operated rats due to fat deposition caused by estrogen deficiency (Zhao et al, 2011). Studies have noted that increased body weight provides an additional stimulus for bone neoformation, serving as a partial protection against the osteopenia that occurs in long bones from supporting body weight (Notomi et al, 2003). In this study, as expected, the final uterus weight was significantly reduced in the OVX group as compared to the sham group, indicating that estrogen deficiency resulted in the atrophy of the uterus of OVX rats.

Leptin administration prevented the loss of uterine weight compared to the OVX group but it still resulted in a lower uterine weight than the sham group. Leptin directly stimulates gonadotropin secretion of the anterior pituitary gland. The mechanism whereby leptin directly stimulates gonadotroph function is not known. There is reason to believe that the effects on hypothalamic GnRH release could be mediated by neuropeptide Y (Baldock et al, 2006). Increased uterine weight in leptin-treated rats seems to occur as a result of proliferative responses to increased ovarian estrogen production. 


\section{Serum Calcium and Phosphorous Levels}

Serum calcium level was significantly decreased while serum phosphorus was non significantly increased in the OVX group as compared to the control group. In this study, hypocalcemia associated with ovariectomy was due to decrease of intestinal calcium absorption and increase of renal excretion of calcium due to estrogen deficiency (Saleh and Saleh, 2011). Estrogen deficiency was associated with changes in expression of many proteins involved in distal tubule calcium reabsorption (Lee et al, 2007).

Leptin administration caused non- significant decrease of serum $\mathrm{Ca}++$ level compared to the ovariectomized rats. Leptin has two opposing effects on calcium metabolism. It has been linked to increased calcium excretion in the kidney. Loss of leptin function contributes to aberrant regulation of renal 25-hydroxyvitamin D3 metabolism by increasing the gene expression of renal $1 \alpha$-hydroxylase, which catalyzes 1,25 -dihydroxyvitamin D3 [1, 25(OH) 2D3] synthesis and thus elevates serum 1, 25(OH) 2D3 concentrations (Matsunuma and Horiuchi, 2007). Increased of calcium level in ovariectomized rats after administration of leptin, was due to increased ovarian estrogen production.

\section{Bone Turnover Biomarkers}

In the present study, the obtained data revealed that the induction of osteoporosis by ovariectomy caused significant increase in skeletal remodeling, as was evidenced by the increased levels of the bone turnover markers, osteocalcin, specific bone alkaline phosphatase and deoxypyridinoline. This elevation of serum osteocalcin concentration in OVX-group indicates an increase in bone turnover, which would result in bone loss so that an imbalance would exist between bone resorption and bone formation (Byun and Lee, 2010).

Leptin prevented the increased rate of bone formation in an effort to restore the disturbed balance of bone turnover. The consequent effect of leptin on bone formation was reflected in the increased levels of circulating osteocalcin observed after ovariectomy.

Plasma alkaline phosphatase was significantly increased in the OVX-rats, indicating an increased osteoblastic activity on bone formation (Alam et al, 2006).

Treatment with alendronate or leptin caused significant decrease of serum alkaline phosphatase and significant increase of serum calcium levels compared with OVX group, but there was no significant difference between both drugs.

With respect to the elevated urinary DPD level in ovariectomized rats, it is well known that bone turnover is increased by ovariectomy and the activity of osteoclasts is higher than that of osteoblasts, hence osteoporosis develops (Hassan et al, 2010). In osteoporosis there was a bone turnover with the resorption exceeding the formation (Li et al, 2002).

Leptin decreases both bone formation and resorption. These decreases are reflected in reductions in serum osteocalcin and BSALP concentrations and in urinary DPD levels. This suggests that leptin prevents OVX-induced increases in bone turnover in rats. Leptin also suppressed the increased body weight of OVX rats and returned it to the sham levels, significantly increased uterine weight compared to OVX rats.
The protective effect of leptin may be due to its peripheral and central action. Peripherally, leptin interacts with bone marrow stromal cells, osteoblasts, and osteoclasts to increase bone mass (Jackson et al, 2011). Leptin increases both expression of osteogenic genes in stromal cells (van Marken et al, 2009) and osteoblast proliferation and decreases osteoclastogenesis (Cirmanová et al, 2008). Centrally, leptin inhibits bone formation by binding to its receptors located in hypothalamus and thereby activating the sympathetic nervous system (SNS), which requires the adrenergic $\beta 2$ receptors (Adrb2) expressed in osteoblasts (He et al, 2011). Downstream of Adrb2, leptin signaling activates molecular clock genes that regulate osteoblast proliferation and hence bone formation (Sato et al, 2007). Leptin also inhibits bone resorption by the stimulation of sympathetic nervous system and CART (cocaine amphetamine regulated transcript) (Elefteriou et al, 2005). In addition to the sympathetic nervous system, leptin also interacts with various hypothalamic neuropeptides, such as neuropeptide Y (Baldock et al, 2006), neuromedin U (Sato et al, 2007) and/or serotonin (Yadav et al, 2006), which might modulate the effects of leptin on bone.

\section{Conclusions}

The results obtained in the present study provide evidence that leptin prevents OVX-induced increases in metabolic bone turnover in rats. Leptin chronic administration has a significant effect in bone formation and bone resorption biomarkers of ovariectomy induced-osteoporosis in rats.

\section{References}

1. Alam R, Kim S, Lee J, Chon S, Choi S, Choi H and Kim N. Effects of safflower seed oil in osteoporosis induced-ovariectomized rats. Amer J Chinese Med 2006; 34 (4): 601-612.

2. Baldock P, Allison S, Mcdonald M, Sainsbury A, Enriquez R, Little D, Eisman J, Gardiner E, Herzog H. Hypothalamic regulation of cortical bone mass: Opposing activity of Y2 receptor and leptin pathways. J Bone Miner Res 2006; 21: 1600-1607.

3. Brown A. Development of serum calcium and phosphorus as clinical biomarkers for drug-indused systemic mineralization. 301-322. In: Bleavins M, Carini C, Jurima-Romet M, Rahbari R (Eds). Biomarkers in drug development: a handbook of practice, application, and strategy. John Wiley \& Sons, Inc., Hoboken, New Jersey, Canada: Chapter 15.

4. Burguera B, Hofbauer L, Thomas T, Gori F, Evans G, Khosla S, Riggs L, Turner R. Leptin reduces ovariectomy-induced bone loss in rats. Endocrinology 2001; 142 (8): 3546-3553.

5. Byun J, Lee S. Effect of soybeans and sword beans on bone metabolism in a rat model of osteoporosis. Ann Nutr Metab 2010; 56: 106-112.

6. Canalis E. New treatment modalities in osteoporosis. Endocr Pract 2010; 29: 1-23.

7. Cirmanová V, Bayer M, Stárka L, Zajičková K. The effect of leptin on bone - an evolving concept of action. Physiol Res 2008; 57 (1): S143-S151.

8. Deal, C. Potential new drug targets for osteoporosis. Nat Clin Pract Rheumatol 2009; 5 (1): 20-27. 
9. Ducy P, Amling M, Takeda S, Priemel M, Schilling AF, Beil F, Shen J, Vinson C, Rueger J, Karsenty G. Leptin inhibits bone formation through a hypothalamic relay: a central control of bone mass. Cell 2000; 100: 197-207.

10. Elefteriou F, Ahn J, Takeda S, Michael Starbuck M, Yang X, Liu X, Kondo H, Richards W, Bannon T, Noda M, Clement K, Vaisse C and Karsenty G. Leptin regulation of bone resorption by the sympathetic nervous system and CART. Nature 2005; 434: 514-520.

11. Hassan N, Hassan R, Abou Setta L, Abd El-moniem M, Ahmed H and Hammouda F. Potent role of dietary phytoestrogen plants cultivated in egypt against osteoporosis in ovariectomized rats. Austr J Basic Appl Sci 2010; 4 (2): 359-369.

12. He J, Jiang L, Dai L. The roles of the sympathetic nervous system in osteoporotic diseases: A review of experimental and clinical studies. Ageing Res Rev 2011; 10: 253-263.

13. Jackson M, Iwaniec U, Turnera R, Wronskib T, Kalra S. Effects of increased hypothalamic leptin gene expression on ovariectomy-induced bone loss in rats. Peptides 2011; 32: 1575-1580.

14. Konturek P, Konturek S, Brzozowski T, Jaworwk J, Hahn E. Role of leptin in the stomach and the pancreas. J Physiol 2001; 95: 345-354.

15. Lee G, Lee K, Choi K, Ryu Y, Paik S, Oh G, Jeung E. Aromatase deficiency induces urinary calcium loss. J Bone Miner Res 2007; 22: 1968-1978.

16. Li X, Hara I, Matsumiya T. Effects of osthole on postmenopausal osteoporosis using ovariectomized rats; comparison to the effects of estradiol. Biol Pharm Bull 2002; 25 (6): 738-742.

17. Matsunuma A, Horiuchi N. Effect of leptin on regulation of renal 25-hydroxyvitamin $\mathrm{d} 3$ metabolism and maintenance of calcium homeostasis. J Oral Biosci 2007; 49 (2): 97-104.

18. Noriyoshi S, Masaru Y, Takemi G, Yoshimitsu A. Stimulation of prostaglandin E2 and interleukin-1ß production from periodontal ligament cells of old rat subjected to mechanical stress. J Geront 2000; 55: B489-B495.

19. Notomi T, Okimoto N, Okazaki Y, Nakamura T, Suzuki M. Tower climbing exercise started 3 months after ovariectomy recovers bone strength of the femur and lumbar vertebrae in aged osteopenic rats. J Bone Miner Res 2003; 18: 140-149.

20. Robling A, Castillo A, Charles H. Turner Biomechanical and Molecular Regulation of Bone Remodeling. Annu Rev Biomed Eng 2006; 8: $455-498$
21. Saleh N, Saleh H. Olive Oil effectively mitigates ovariectomyinduced osteoporosis in rats. BMC Complement Altern Med 2001; 11: 10.

22. Sato S, Hanada R, Kimura A, Abe T, Matsumoto T, Iwasaki M, Inose H, Ida T, Mieda M, Takeuchi Y, Fukumoto S, Fujita T, Kato S, Kangawa K, Kojima M, Shinomiya K, Takeda S. Central control of bone remodeling by neuromedin U. Nature Med 2007; 13: 1234-1240.

23. Sheweita SA, Khoshhal KI. Calcium metabolism and oxidative stress in bone fractures: role of antioxidants. Curr Drug Metab 2007; 8: 519-525.

24. Stavropoulou A, Christopoulou G, Anastassopoulos G, Panteliou S, Lyritis G, Spiliotis B, Karamanos N, Panagiotopoulos E, Lambiris E. Alteration in serum leptin correlates with alterations in serum N-telopeptide of collagen type I and serum osteocalcin during the progression of osteoporosis in ovariectomized rats. Clin Chem Lab Med 2005; 43 (12):1359-1365.

25. Tarek A, Hala S. Role of histamine in ovariectomy-induced osteoporosis in rats. Bull Alex Fac Med 2006; 42 (3): 833-839.

26. Turkozan N, Ulusoy A, Balcioglu H, Bal, F, Ozel S. The effects of ovariectomy and naproxen treatment on the strength of femoral midshaft and molar alveolar region in rats. Int J Morphol 2009; 27 (3): 659-666.

27. van Marken L, Vanhommerig J, Smulders N, Drossaerts J, Kemerink G, Bouvy N, Schrauwen P, Teule G. Cold-activated brown adipose tissue in healthy men. New Engl J Med 2009; 360 (15): 976-989.

28. Weitzmann M, Pacifici R. Estrogen deficiency and bone loss: an inflammatory tale. J Clin Investig 2006; 116 (5): 1186-1194.

29. Wronski T, Walsh C, Ignaszewski L. Histologic evidence for osteopenia and increased bone turnover in ovariectomized rats. Bone 1986; 7: 119-123.

30. Xiong H, Wei L, Hu Y, Zhang C, Peng B. Effect of alendronate on alveolar bone resorption and angiogenesis in rats with experimental periapical lesions. Intern Endodontic J 2010; 43: 485-491.

31. Yadav V, Oury F, Suda N, Liu Z, Gao X, Confavreux C, Klemenhagen K, Tanaka K, Gingrich J, Guo X, Tecott L, Mann J, Hen R, Horvath T, Karsenty G. A serotonin-dependent mechanism explains the leptin regulation of bone mass, appetite, and energy expenditure. Cell 2006; 138 (5): 1500-1508.

32. Zhao X, Wu Z, Zhang Y, Yan Y, He Q, Cao P, Lei W. Anti-osteoporosis activity of Cibotium barometz extract on ovariectomy-induced bone loss in rats. J Ethnopharmacol 2011; 137: 1083- 1088.

Received January 18, 2012. Accepted January 23, 2012. 